\title{
Multiple cerebral cystic lesions with calcified borders: an atypical presentation of pulmonary adenocarcinoma
}

\author{
Álvaro Machado · João Soares-Fernandes · \\ Carla Ferreira $\cdot$ Jaime Rocha
}

Received: 21 March 2007/Accepted: 3 May 2007/Published online: 14 June 2007

(C) Springer Science+Business Media B.V. 2007

Keywords Brain metastasis - Calcification · Cystic . Pulmonary $\cdot$ Adenocarcinoma

A 56-year-old woman presented with a two-month history of behavioural disturbance. Examination disclosed receptive dysphasia and right hemianopsia. Brain CT (A: before and B: after contrast injection) and MRI (C: fluidattenuated inversion-recovery sequence; D: T1-weighted images with gadolinium) showed multiple cystic lesions with calcified borders and discrete peripheral contrast enhancement, without surrounding edema (Fig. 1). Echinococcosis and cysticercosis serologies were negative. Thoracic CT revealed two lung nodules in the right superior and inferior lobes. Abdominal CT showed a hepatic solid lesion. Transthoracic needle biopsy of the largest pulmonary lesion allowed the diagnosis of primary adenocarcinoma. Supportive treatment only was offered. She died two weeks later. Autopsy was not allowed.

Calcification of metastatic brain lesions is exceedingly rare, with less than 60 cases reported to date. Malignancy and high-growing velocity usually prevents time-dependent calcium deposition. For this reason calcification tends to occur in very slow-growing tumours, indicating a better prognosis. In the reported case other factors than time, one of which probably being cyst composition, certainly concurred to this unusual clinical finding.

Acknowledgments Luís Monteiro, MD PhD, Professor of Neurology, Hospital Geral de Santo António, Porto, Portugal. João Cunha, MD, consultant pneumologist, Hospital de São Marcos, Braga, Portugal.
Á. Machado $(\square) \cdot$ C. Ferreira

Neurology Department, Hospital de São Marcos,

Largo Carlos Amarante, Apartado 2242, Braga, Portugal

e-mail: alvmac@gmail.com

J. Soares-Fernandes · J. Rocha

Neuroradiology Department, Hospital de São Marcos, Braga,

Portugal 

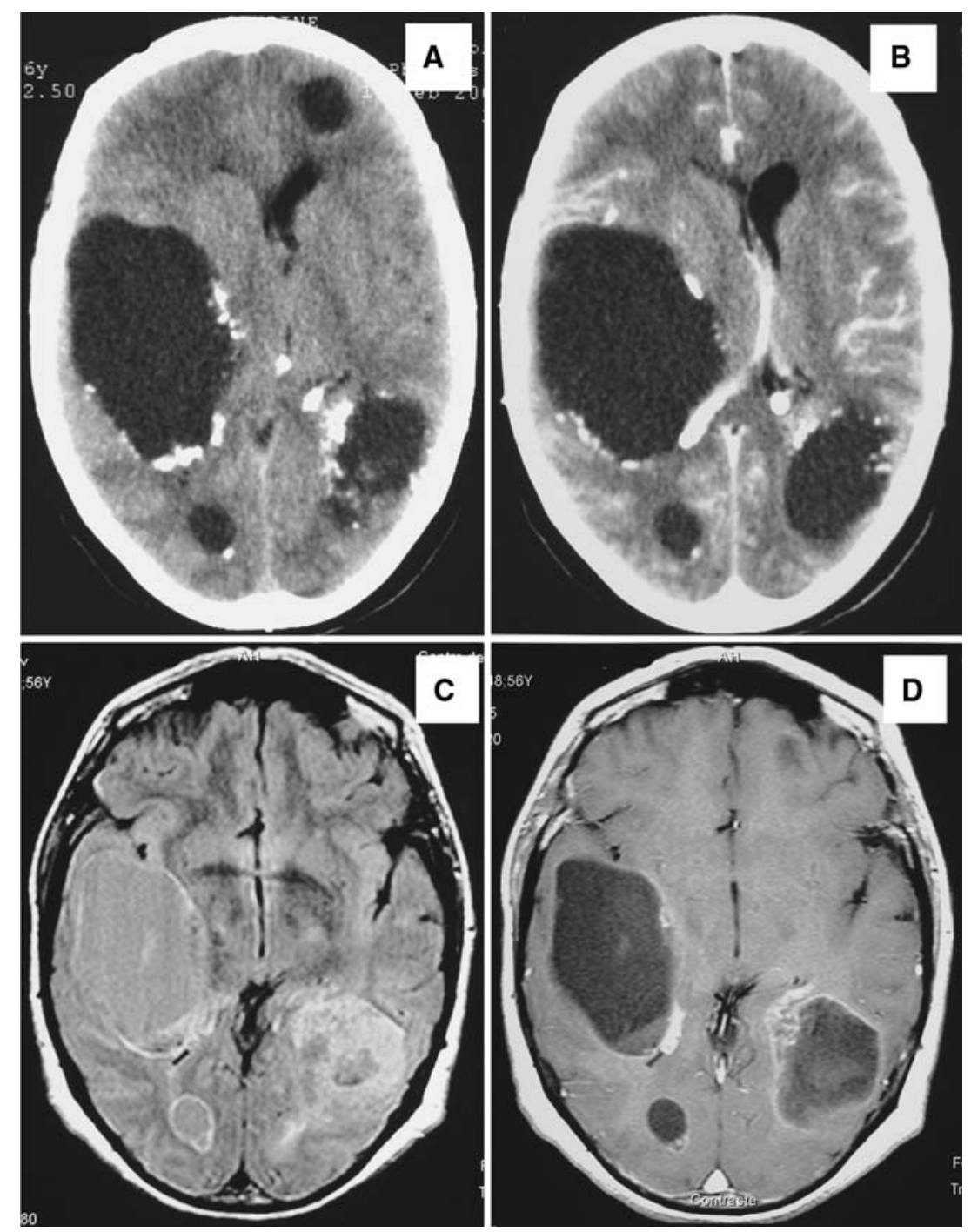

Fig. 1 